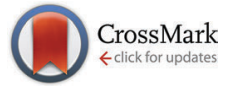

Cite this: Phys. Chem. Chem. Phys., 2015, 17, 27900

DOI: $10.1039 / c 5 c p 90177 d$

www.rsc.org/pccp

\section{Correction: Temperature-dependent energy levels and size-independent thermodynamics}

\author{
Rodrigo de Miguel \\ Correction for 'Temperature-dependent energy levels and size-independent thermodynamics' by \\ Rodrigo de Miguel, Phys. Chem. Chem. Phys., 2015, 17, 15691-15693.
}

On page 15692, the paragraph leading up to eqn (13) and eqn (13) itself should be amended as follows:

If there is only enough energy for one of the $N$ particles to be in the upper level, then the system will have multiplicity $N$. By enforcing the condition that when $n=1$ the temperature must be equal to $\varepsilon /\left(k_{\mathrm{B}} \ln N\right)$, we obtain $\left\langle\mathrm{d} \mathcal{E}_{\mu} / \mathrm{d} T\right\rangle=k_{\mathrm{B}}(1+\ln N-\mathrm{H}[N-1])$, and the energy $\mathcal{E}$ finally results in

$$
\mathcal{E}=(1+\ln N-\mathrm{H}[N-1]+n(\mathrm{H}[N-n]-\mathrm{H}[n])) k_{\mathrm{B}} T .
$$

The Royal Society of Chemistry apologises for these errors and any consequent inconvenience to authors and readers. 